


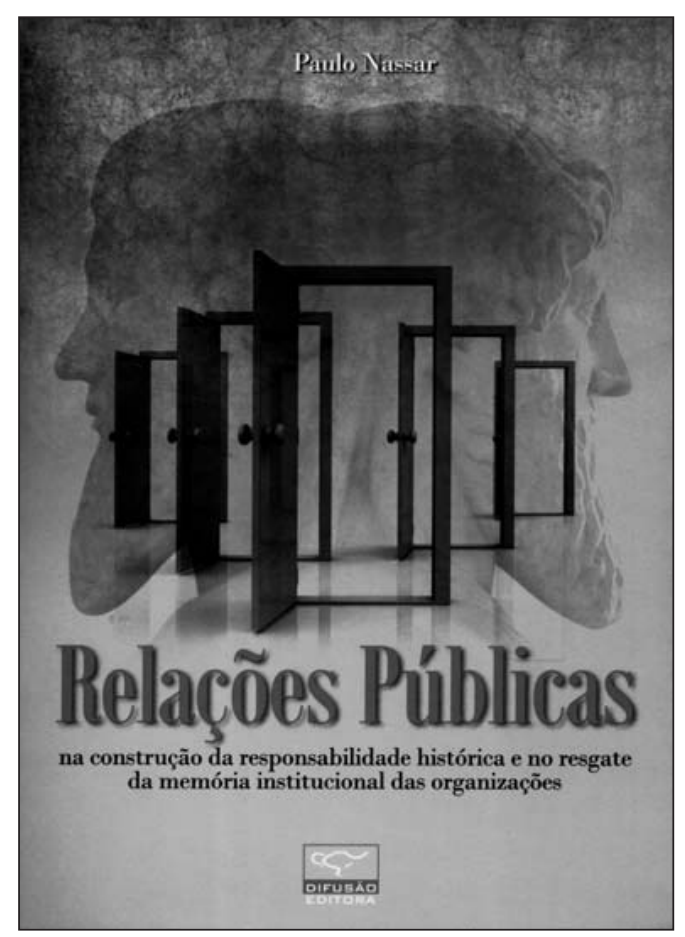

Paulo Nassar

Relações Públicas na construção da responsabilidade histórica e no resgate da memória institucional das organizações

São Caetano do Sul, SP:

Difusão Editora, 2007.

206 páginas

Ivone de Lourdes Oliveira

- Doutora em Comunicação

e Cultura pela Universidade Federal do Rio de Janeiro (UFRJ)

- Professora do Programa de Mestrado em Comunicação Social da Pontifícia Universidade Católica de Minas Gerais (PUC-MG)

- Diretora da Faculdade de Comunicação e Artes da PUC-MG

- Pesquisadora da área de Comunicação Organizacional e Relações Públicas

- Vice-diretora da Associação Brasileira de Pesquisadores em Comunicação Organizacional e Relações Públicas (Abrapcorp)

- ivone@pucminas.br 


\section{Visão conceitual e crítica das Relações Públicas numa perspectiva da responsabilidade histórica e social das organizações}

$\mathrm{O}$ portuna e inédita foi a opção de Paulo Nassar em trabalhar a temática das Relações Públicas na construção da responsabilidade histórica e no resgate da memória institucional das organizações, que agora ganha corpo em livro. $\mathrm{O}$ texto é resultado da sua tese de doutorado, apresentada à Escola de Comunicações e Artes da Universidade de São Paulo (ECA-USP) em agosto de 2006. Esta obra reforça em nós, profissionais e acadêmicos da área de Comunicação Organizacional e Relações Públicas, o sentimento de maturação do campo em sua dimensão mais integrada e estratégica e contribui, de forma relevante, para a construção de um corpus científico que envolve os aspectos conceituais e práticos da área.

Oportuna porque localiza, com propriedade epistemológica e conceitual, a Comunicação Organizacional e as Relações Públicas em um campo científico, no qual o conhecimento é construído com base na contribuição de outros campos das ciências sociais aplicadas, tais como Administração, Marketing, Antropologia, Política, Sociologia e, oportunamente, a História. O autor opta por partir de pressupostos epistemológicos que já encontram ressonância no meio acadêmico específico e isso torna sua produção assertiva e propositiva, além de mais pertinente à representação da prática da comunicação nas organizações, uma vez que a complexidade da realidade traz consigo a perspectiva da transdisciplinaridade.

Inédita porque, ao elucidar a imbricação entre Relações Públicas, Comunicação e história empresarial, o autor demonstra como o resgate da trajetória das organizações, por meio da sistematização e preservação dos saberes e experiências vividas, pode atribuir valor estratégico ao negócio. O material simbólico existente nas organizações pode ser trabalhado estrategicamente, o que reforça os relacionamentos com os funcionários, bem como com a comunidade, a imprensa e a sociedade.

Ao abordar a história empresarial com base em referenciais teóricos como Bourdieu, na discussão entre simbólico e conceito de campo, e Worcman, com as perspectivas e metodologias históricas que possibilitam o resgate da memória das organizações por meio da história oral, Paulo Nassar revitaliza a discussão sobre identidade e imagem institucionais. Mais do que isso, ele coloca sob novo enfoque a missão, lendas e mitos internos, rituais de celebração, heróis, documentos, fotografias e materiais simbólicos que constituem a dimensão cultural inerente a qualquer trajetória de vida, inclusive das organizações.

O autor também dá novo fôlego à abordagem social que, para além dos aspectos fi- 
nanceiros e econômicos, atribui às organizações uma dimensão simbólica e afetiva de responsabilidade sob suas ações em um caráter de produção e interação social, na construção de uma história particular, inserida nos contextos social, político e cultural.

A responsabilidade histórica encontra-se com a recente produção e discussão sobre o compromisso social das organizações. Como analisa Nassar, o grande desafio dessa perspectiva, que é uma tendência no meio empresarial, é "identificar se a motivação que leva as empresas ao resgate da história é genuína ou se representa mais um nicho a ser explorado pelo Marketing" (p.173).

Essa análise crítica perpassa todo o livro. O autor deixa transparecer a consciência de que os aspectos simbólico e qualitativo são motivadores do trabalho das Relações Públicas nas organizações, trabalho esse "imbuído de humanismo". A opção em enveredar pela história e elucidar pontos de imbricação dessa ciência com a prática da Comunicação Organizacional, principalmente na perspectiva do resgate, é uma contribuição metodológica naquilo que diz respeito às técnicas de coleta de dados como, por exemplo, a história oral.

Ler esta obra é reconfortante. Teoricamente bem trabalhada, ela leva à superação das disputas internas do campo e dos entraves conceituais que, ainda existentes, dificultam o entendimento do trabalho integrado e da abordagem transdisciplinar, que requer conhecimento e prática da Comunicação Organizacional e das Relações Públicas.

Paulo Nassar resgata a produção acadêmica referencial das Relações Públicas, como Margarida Kunsch e Roberto Porto Simões, e abre portas para o diálogo com outros campos, o que faz com que sua narrativa, além de revitalizar discussões que há muito fazem parte das temáticas freqüentemente problematizadas, adquira uma projeção de futuro, direcione-se para frente e aponte novas perspectivas para as Relações Públicas.

O livro é constituído de quatro capítulos articulados e fundamentados nos quais o autor parte de um levantamento histórico das Relações Públicas e apresenta aspectos que constituem a identidade das Relações Públicas, desde seu surgimento. Localiza a atividade no Brasil, com sua precipitada regulamentação no contexto da ditadura, e apresenta seus aspectos políticos, de formação da opinião pública e de construção de relacionamentos. Aborda, ainda, sua interface com a administração e seu papel essencial na criação de identidade das organizações e na sociedade informacional, além do seu aspecto contemporâneo de protagonista social.

Nassar constrói a imbricação da história com Relações Públicas e Comunicação Empresarial com muita destreza e, para não fugir de sua veia poética, com poesia. Mostra como a narrativa histórica e o discurso, como registros, são carregados de emoções e afetos e como se encontram com o universo empresarial e se tornam "pilares da me- 
mória" (p.111), formando a personalidade e a imagem de uma organização. Fatos, documentos e pessoas são materiais simbólicos que constituem a memória empresarial.

As organizações têm atuação histórica, buscam legitimar suas ações e validar-se publicamente e é justamente na sistematização dos dados e materiais produzidos que elas resgatam sua memória. Aí está a grande diferença dessa obra. É instigante e leva à reflexão, vislumbrando mais uma oportunidade de atuação estratégica das Relações Públicas por meio do resgate da memória. A proposta do autor está respaldada na análise de cases empresariais e da pesquisa empírica e mostra que a configuração da responsabilidade histórica tem se apresentado como prática nas organizações no Brasil.

Relações Públicas na construção da responsabilidade histórica e no resgate da memória institucional das organizações é uma obra que supera. Supera as discussões menores de disputa pelo campo da Comunicação Organizacional e, para isso, apresenta a transdisciplinaridade como perspectiva de análise e de trabalho. Supera a fragilidade epistemológica tão frequiente nas produções acadêmicas da área e, para isso, opta por autores pertinentes à temática e por enfoques coerentes com aquilo que é próprio das Relações Públicas: o gerenciamento estratégico do simbólico. Supera modismos e apresenta, por meio de uma pesquisa bibliográfica e empírica com empresas representativas do contexto empresarial brasileiro, uma tendência da prática das Relações Públicas. 


\section{Outras publicações de referência}

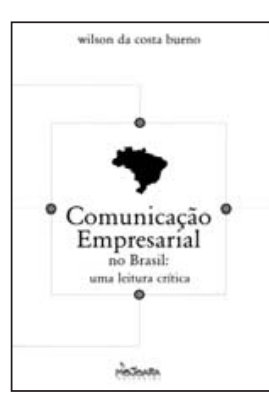

Comunicação

Empresarial no Brasil:

uma leitura crítica

Wilson da Costa Bueno

São Paulo:

Majoara Editorial,

2007

200 páginas

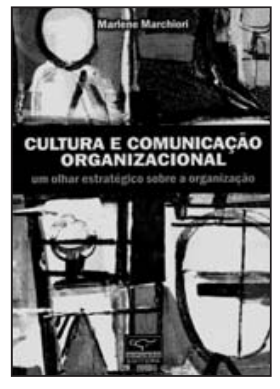

Cultura e Comunicação

Organizacional: um

olhar estratégico

sobre a organização

Marlene Marchiori

São Caetano do Sul, SP:

Difusão Editora,

2006

260 páginas

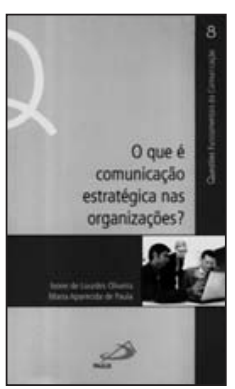

0 que é comunicação

estratégica

nas organizações?

Ivone de Lourdes

Oliveira e Maria

Aparecida de Paula

São Paulo: Paulus, 2006

80 páginas

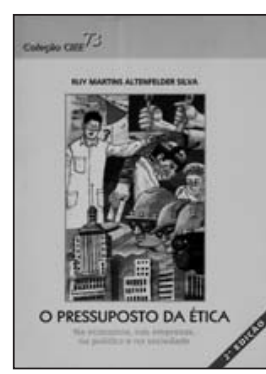

0 pressuposto da ética: na economia, nas empresas, na política e na sociedade

Ruy Martins

Altenfelder Silva

São Paulo: CIEE, 2004

148 páginas

Unesp/Faac, 2005

352 páginas 